\title{
STRATEGY FOR DEVELOPMENT OF BULGARIAN CULTURE 2019-2029. OPPORTUNITIES AND CHALLENGES
}

\section{Kazashka, Vesela, vesela.kazashka@gmail.com}

Academy of Music, Dance and Fine Arts „Prof. Asen Diamandiev" Plovdiv, Bulgaria

\begin{abstract}
Bulgarian culture is multi-layered and has been formed during different historical epochs, which affect the Bulgarian nation and identity. Bulgaria is one of the countries with the richest cultural heritage, which allows for the use of this unique resource. Adequate and effective policies for preservation of this valuable resource, formulation of clear priorities, goals, tasks and mechanisms, ensuring accessibility of citizens to culture and art, their recognition by the society, are of special importance for the message of civilization, which we must preserve and we hand over. Cultural education is one of the main aspects of its preservation.
\end{abstract}

Keywords: Cultural Policies, Art, Culture

\section{СТРАТЕГИЯ ЗА РАЗВИТИЕ НА БЪАГАРСКАТА КУАТУРА 2019-2029. ВЪЗМОЖНОСТИ И ПРЕАИЗВИКАТЕАСТВА}

\section{Казашка, Весела, vesela.kazashka@gmail.com}

АМТИИ „Профр. Асен Аиамандиев", Пловлив, България

Резюме: Българската култура е многопластова и се е одрормя^а през различни исторически епохи, които се отразяват на българската народност и илентичност. България е еАна от страните с най-богато културно наслеАство, което Аава възможност за използване на този уникален ресурс. ААекватни и ефективни политиките за съхранение на този ценен ресурс, формулиране на ясни приоритетите, цели, залачи и механизми, осигуряване на Аостьпност на гражАаните Ао култура и изкуство, припознаването им от обществото, са от особено значение за цивилизационното послание, което трябва да съхраним и предалем. Образованието в областта на културата е еАин от основните аспекти за нейното опазване.

КАючови Ауми: културни политики, изкуство, Култура 
Културата като най-ярко проявление на цивилизацията е приоритет на всяка дьржава. Културата е свързана с образованието, науката, изкуството, мичностното развитие на човека. През 2010 година Петя Бъркалова и Весела Казашка фрормулират пет посоки на еволюционното и емоционално развитие на човека и обществото: изкуството приложение на творческите учения и въображение на човека, за съзАаване на красота и емоции; науката-разума, теорията, технологиите и иновациите като съзАания на човешкия интелект; образованието обучението, наследяването на знанието, предаване на опит и знания, създаване на отношение към ученето; културата - чувството за иАентичност и принаАлежност. Не на послеАно място - личното развитие на човека като Аичност и като част от обществото, което вкАючва наука, изкуство, образование и култура (Barkalova, Kazashka, 2010).В този контекст националните и европейски културни политики са от основополагащо значение за съхранението на културата и по-широкото разпространение.

Още през 1998 голина Аандри и колектив (комисия) установяват, че българската културна политика все още не разполага с концепция за българската култура и културен живот. Те констатират закостенялост в начина на работа и мислене, като това е елин от най-трудните за преолобяване проблеми, спореА тях. Те ясно полчертават необхолимостта от национален дебат, в който $А$ се вкАючи широка аудитория с желание за промяна. (Landry, 1997). Три са основните препорьки, които комисията дава на Бьлгария през 1998 г.:

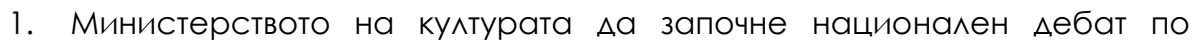
проблемите на културата, обвързан с меморандум, одобрен от правителстовто за запазване настоящото равнище на културните субсилии, с отчитане на инорацията, така че дебатьт $\Delta а$ може $\Delta а$ протече при стабилни фринансови предпоставки.

2. Преосмисляне на ролята на читалищата като ключов фрактор за развитието на културата, а също така и за активизиране на гражАанското общество.

3. Активно общуване на България с най-Аоброто от европейската културна политика. 
В резултат на Аалените препорьки и активността на работещите в сорерата на културата и изкуството към фревруари 2021 има постигнати резултати, които са Аобра стьпка, но недостатьчна. През 2010 голина е утвьрдена е метолология за изготвяне на национална стратегия за развитие на изкуствата, културното наслеАство, културни и творчески индурстрии, и културен туризъм в България. През 2011-2012 година е направен опит за фоормиране на Стратегия за развитие на българската култура. Сорормирани са работни групи, с участието на организаци, културни Аейци, изслеАователи, включено е проучване на чужАите практики, провежлане на Аискусии. ПредвижАа се изработване на национална програма и стратегически план. Определени са стратегически цели и приоритети на Министерството на културата през 2015 голина. През 2019 голина е представена Стратегия за развитие на българската култура 2019-2029 година, която още не е приета' . Кабаков определя изработването на стратегия за развитието на културата като елемент в процеса на стратегическото управление на културата с определящо значение (Kabakov, 2017). Невена Аобрева представя врьзката межлу стратегическото планиране с тьрсенето на най-доброто позициониране спрямо външната срела и преллага управление на процесите чрез постигане на цели, които са поставени в бълещето (Dobreva, 2018). Според Mercer културата не може $л а$ бъ $А$ разглежлана изолирано от Аругите сорери като например образованието и на местно ниво културното планиране е важен елемент от стратегиите за развитие на грала и средата (Mercer, 1991). СпореА Ghilardi културата от особено важно и решаващо значение за общественото благоденствие (Ghilardi, 2011).

\section{СТРАТЕГИЯ ЗА РАЗВИТИЕ НА БЪАГАРСКАТА КУАТУРА 2019-2029}

Необходимостта от обща стратегия отразява желанието на работещите в сорерата на културата и на министерството на културата за анализиране на проблемите, свързани с управление на културата,

1 Strategy for Development of Bulgarian Culture 2019-2029 (Draft), Ministry of Culture, Sofia 2019, // [Стратегия за развитие на българската култура 2019-2029 голина (предложение), Министерство на културата, Софрия 2019] 
дефриниране на потенциални решения и формулиране на краткосрочни цели, залачи, отговорници, чрез които да се постигне цялостното изпьлнение на стратегията и $а$ б бьлат сьзАалени условия за развитие на българската култура.

\section{Цели и заАачи}

В процеса на изгражлане на стратегията се обособяват няколко взаимосвързани етапа, които дефинират проблема, анализират срелата, формулират потенциални решения. Фигура 1 представя визията на стратегията за развитие на българската култура, разработена на анализ на предходния 10 годишен периол и със значение на стратегически Аокумент за слеАващите 10 години.

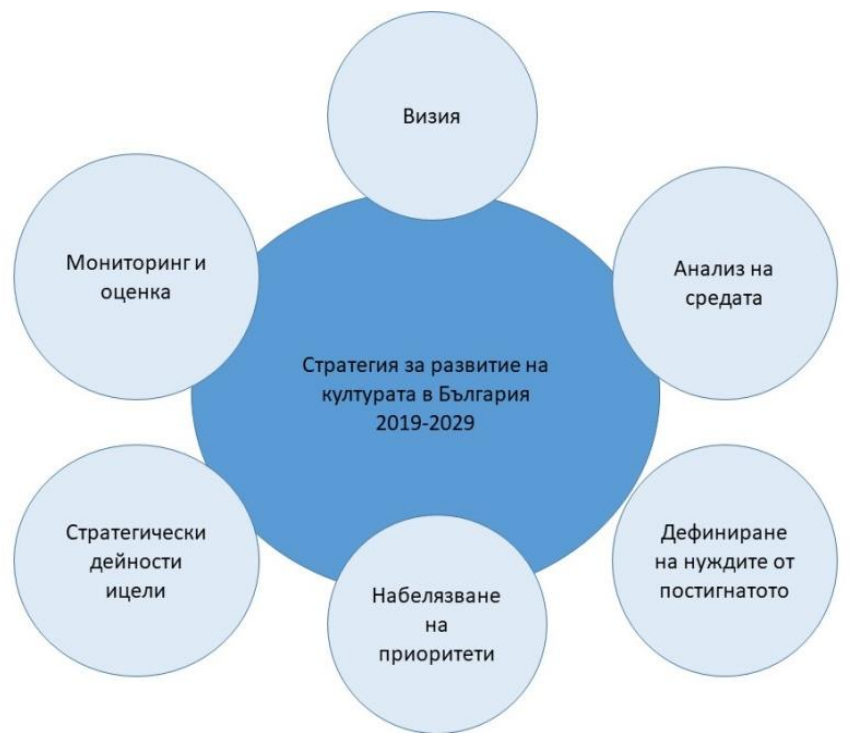

Фиг.1. Стратегия за развитие на културата 2019-2029

Стратегията е „жив" Аокумент, който при необходимост Аа бъде актуализиран. Този фракт изисква още по-решително приемане на Аокумента, с цел изпьлнение на заложените залачи и приоритети. [Фиг.1] Културата е възприемана като начин на живот, свързан със съзАаване на културно съдьржание, осмисляне и участие в процеса на изграждане на нови фрорми на сьдьржание, на нови публики. 
В стратегията са формулирани ясните ангажименти на дьржавата по отношение на културата, а именно: създаване на условия за полпомагане и развитие на културните процеси, на творческите индустрии и иновации в контекста на европейските и световни тенденции, така и по отношение на съхранение на тралициите и бъ^гарската национална илентичност; превръщане на твореца в активен участник на създаване на съвременна култура; създаване на нови културни пространства, Ао които всеки Аа има Аостьп с це^ заловоляване на своите културни потребности; утвьржАаване на мястото на българската кулкура като част от общата европейска и световна култура; превръщането на културата в стратегически ресурс за устойчиво социално и икономическо развитие. ИзвеАени са и селем основни принципа, на които Аа бъле основано настоящото и бълещето развитие на културата:

1. Аецентрализация на управлението и оринансирането на културата -

2. Свобода на действието и орормиране на пазарно ориентирано поведение на културните институции и творците.

3. Промени в културното законодателство, преАназначени $\Delta а$ посрещнат новите социално-икономически преАизвикателства.

4. Изгражлане на полходяща срела, улесняваща културното развитие в контекста на членството на България в Европейския съюз.

5. Равнопоставеност на дьржавните, общинските и частните културни институти И институции.

6. Активно присъствие и участие на всички нива на неправителствения сектор.

7. Управление на културата, основано на участието на всички заинтересовани страни, с ясни функции и отговорности.

\section{В Стратегията за развитие на българската култура 2019-2029 гоАина} приоритетно се поставя вижАането за развитие на нови форми и

политики. Осъществяването на това виждане е свързано с непрекъснат анализ на културните процеси и актуализация на заложените цели. Постигането на подобно състояние на културата изисква подкрепа на стратегически значими инициативи като опазването и насърчаването на културното многообразие, творческата мобилност и защитата на интелектуалната собственост в областта на културата, развитие на 
Съвременни форми на културно изразяване и не на послеАно място качествено образование в областта на изкуствата и културата.

В стратегическо отношение основният приоритет е насочен към създаване на подходяща законодателна среда (Това се налага от необхолимостта от актуализиране на действащото законолателство преАвиА новите условия на развитие, както и промените настьпващи в общоевропейски план) и разработване и прилагане на нов тип фонансови механизми.

\section{Сренно образование в областта на културата и изкуството}

Основен приоритет на образованието в сорерата на културата и изкуството е полобряване качеството на образование и повишаване на мотивацията на обучаеми и преполаватели. Пьрвата стратегическа цел заложена в стратегията е качествено образование в системата на средните училища по изкуства и по култура. Качественото образование се влияе от Ава фокктра - инорраструктура - материална база, техническо обезпечаване и ниво на експертния капацитет и педагогически качества на преподавателският сьстав. Към момента финансирането на училищата е на базата на Аелигирани бюАжети с основен показател, който влияе на размера на фринансирането - броя на учениците. Стратегически, с цел полобряване на качеството в образованието по изкуства и култура е залагането на качествен показател при оценката на училищата - качество на предоставеното образование, получени резлутати, степен на удовлетвореност и реализация на учениците. Необхолимо е и разработването на нови материали и програми за профресионална подготовка на специалистите със сренно образование, като основен елемент в тях е практическото обучение, стаж в реална работна среда, а също и обучение ориентирано към нуждите на пазара на труда в областта на изкуството и културата.

Насьрчаването на художествено-творческата Аейност на м^алите таланти в среАните училища по изкуствата и културата също е важна стратегическа цел. Мотивацията е чрез стипендии, фринансова помощ, участие в майсторски класове, ^агери, пленери. Развитието на преполавателският състав е срел приоритетите, свьрзани с образование 
в областта на културата и изкуството и заложени в стратегията. Кариерното израстване на преподавателският персонал показва загрижеността на правителството за качествено образование и създаване на у словия за привличане, развитие и зальржане на персонала. Престижьт на профессията и фринансовите стимули са среА мерките за мотивиране на преполавателите.

Значителни са ползите за мичността и за обществото от профресионалното образование, ранното откриване и насьрчаване на

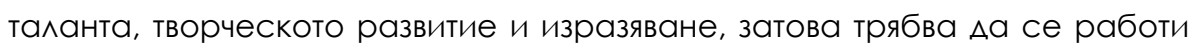
по този въпроси от по-ранна възраст на децата. В стратегията е формулирано, че: „Проучването на местата за профресионална реализация на м^алите специалисти с оглеА съзАаването на по-Аобри и повече работни места е полкрепа за творчеството и иновациите в областта на културата, които са основните Авигатели на интелигентния растеж, мислен като еАин от факторите за изхол от икономическата криза и за преврьщането на съвременните общества и икономики в общества и икономики на знанието."

\section{Висше образование в областта на изкуствата и културата}

Висшите училища в областта на културата се явяват второстепенни разпоредители на бюАжет към Министерството на образованието и науката. Нужлите в сорерата на висшето образование са схолни, като тези във среАното образование по изкуства, а именно: подобряване на научната и художествено-творческа инораструктура, осъвременяване на учебни програми, въвеждане на иновативни подходи

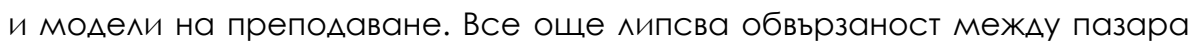
на изкуство и образователните институции, наблюАава се тенденция на тьрсене на реализация в чужбина от м^алите профресионалисти.

Обучение в хибридни специалности, интерАисциплинарност на обучението са среА приоритетите на МОH и висшите училища. Въвежлането на форои на следлипломна квалифиикация, провежленето на тематични научни форуми, създаване на акалемична срела 3 а студенти и преподаватели са среА приоритетите на висшите училища.

Развитие на педагогиката на наследството, насочена към Аеца, ученици и млалежи, интензифрициране на научните изследвания в 
областта на културата са среА приоритетите на висшите училища по изкуства. В изАанието "Статистиката за култура"2 на Евростат за 2019 година преАставя статистически Аанни, свързани с културата и висшето образование. Авторите подчертават, че за целите на изследването пол стуленти в област изкуство и култура на висшето образование най-често се разбират: изкуства; хуманитарни науки и езици; журналистика и инорормация, архитектура и градоустройство. В процентно съотношение Евростат представя студентите в области на висшето образование, свързани с култура като \% от дела на всички студенти в страните от Европейския съюз.

СпореА и доклала за 2019 голина студентите в областта на културата и изкуството в България преставляват 9,4\% от общия брой стуленти в страната. През 2017 година за ЕС - 28 общия брой на студентите по изкуства е приблизително 3 милиона или около 15\% от вСИчкИ стуАеНТИ в ЕС. ЕАинствено България (9.4\%) и Аатвия (9.7\%) са посочели еАноцифррени числа в някои от показателите, които са оценявани.

Архитектура и градоустройство

Журналистика и информация

Хуманитарни науки и езици

Изкуства

Общо

0

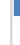

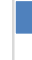

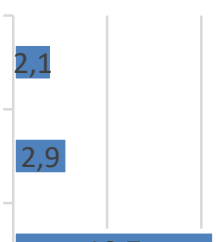
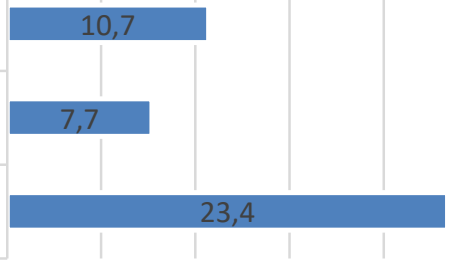

10

Фиг.2. Стуаенти от различни области на висшето образование, свързани с култура, 2017 в хияяАи

2 Cultural statistics 2019 edition, Statistical book, Eurostat https://ec.europa.eu/eurostat/about/policies/copyright Print: ISBN 978-92-76-09703-7 PDF: ISBN 978-92-76-09702-0 doi:10.2785/824495 doi:10.2785/118217 Cat. No: KS-01-19712-EN-C Cat. No: KS-01-19-712-EN-N 
Във фриг. 2 е представено разпрелелението на студентите в България по описаните по-горе четири направления.[Фиг.2]. Както е видно от фригурата по-горе, най-голям процент от студенти в областта на културата и изкуствата са тези, които се обучават в областта на хуманитарните науки и изучаването на чужди езици. Това обучение се провежаа в класическите университети в страната чрез техните хуманитарни фракултети.Четирите най-големи висши учебни заведения в България, които обучават студенти само в областта на изкуството и културата са: Националната музикална акалемия „Профр. Панчо Владигеров" - София, Националната художествена акацемия - Софрия, НАТФИЗ „Крьстьо Сарафов" - Софиия. ЕАинственото учебно заведение в областта на културата и изкуството извьн Софиия е АМТИИ „Проор. Асен АиаманАиев" - ПАовАив.

Обект на настоящия АокАал представлява фринансирането на обучението на студентите [Фиг.3] и размерьт на фринансиране за специфичната научна и художествено-творческа Аейност [Фиг.4] именно на университетите по изкуства за през последните 3 години (2019-2021). Посочените Аанни са получени от постановленията на Министерския съвет за изпьлнението на Аьржавния бюАжет на Република България за съответните гоАини, както слеАва: ПМС³ 344/21.12.2018 г. за изпьлнението на бюлжета на РБългария за 2019 г, ПМС 4 381/30.12.20219 г. за изпьлнението на Аьржавния бюджет на Република Бьлгария за 2020 г., ПМС5 408/23.12.2020 за изпьлнението на Аьржавния бюАжет на Република България за 2021 г.

3 Decree of the Concil of Ministers of The Republic of Bulgaria 344/ 21.12. 2018, // [ПMC 344/21.12.2018 голина за изпьлнението на бюАжета на Република България за 2019 г.] 4 Decree of the Concil of Ministers of The Republic of Bulgaria 381/ 30.12.2019, // [ПМC 381/30.12.20219 голина за изпьлнението на Аьржавния бюлжет на Република България за 2020 г.]

5 Decree of the Concil of Ministers of The Republic of Bulgaria 408/23.12.2020, // [ПMC 408/23.12.2020 за изпьлнението на Аьржавния бюАжет на Република България за 2021 г.] 


\begin{tabular}{|c|c|c|c|c|c|c|}
\hline ВУ3 & $\begin{array}{l}\text { СУМА B } \\
\text { АЕВA } \\
2019\end{array}$ & $\begin{array}{l}\text { БРОЙ } \\
\text { СТУАЕНТИ } \\
2019\end{array}$ & $\begin{array}{l}\text { CУMA } \\
\text { B } \wedge \text { BA } \\
2020\end{array}$ & $\begin{array}{l}\text { БРОЙ } \\
\text { СТУАЕНТИ } \\
2020\end{array}$ & $\begin{array}{l}\text { CУMA B } \\
\text { AEBA } \\
2021\end{array}$ & $\begin{array}{l}\text { БРОЙ } \\
\text { СТУАЕНТИ } \\
2021\end{array}$ \\
\hline $\begin{array}{l}\text { АМТИИ "Профр. Асен } \\
\text { Аиамандиев" - } \\
\text { П^овАив }\end{array}$ & 3404,90 & 742,00 & 3408,80 & 725,00 & 4174,40 & 705,00 \\
\hline $\begin{array}{l}\text { Национална } \\
\text { акалемия за } \\
\text { театрално и } \\
\text { ориммово изкуство } \\
\text { "Крьстьо Сарафоов" - } \\
\text { Содия }\end{array}$ & 4636,90 & 756,00 & 5079,10 & 797,00 & 5213,70 & 812,00 \\
\hline $\begin{array}{l}\text { Национална } \\
\text { музикална } \\
\text { акалемия "Профр. } \\
\text { Панчо В^алигеров" - } \\
\text { Содия }\end{array}$ & 4770,20 & 697,00 & 5223,50 & 719,00 & 49977,30 & 699,00 \\
\hline $\begin{array}{l}\text { Национална } \\
\text { художествена } \\
\text { академия - Соория }\end{array}$ & 5513,50 & 1053,00 & 6403,20 & 1062,00 & 5994,20 & 1072,00 \\
\hline
\end{tabular}

\section{Фиг.3. Финансиране на обучението и брой стуАенти на ВУЗ по изкуствата}

Освен фоинансирането на обучението университетите получават средства за присъщата на висшето училище научна или художественотворческа дейност, както и за издаване на учебници и научни трудове. Финансирането се разпределя на проектния принцип и има за цел $\Delta а$ стимулира колективи от Вузовете да стартират осъществяването на свой проект сьс екип, на залача, която би могла $А$ прерасне в по-голям проект и Аа получи финансиране на следващи нива - национални или межлународни. Финансирането е обвързано и с Аействително показани резултати от преАхонната година.

\begin{tabular}{|c|c|c|c|}
\hline ВУЗ & $\begin{array}{l}\text { СУМА В } А \text { ЕА } \\
2019\end{array}$ & $\begin{array}{l}\text { СУМА В } \\
\text { АЕВA } 2020\end{array}$ & $\begin{array}{l}\text { СУМА В АЕВА } \\
2021\end{array}$ \\
\hline $\begin{array}{l}\text { АМТИИ "Профр. Асен Аиамандиев" - } \\
\text { П^ОвАив }\end{array}$ & 65084,00 & 63810,00 & 53402,00 \\
\hline $\begin{array}{l}\text { Национална акалемия за } \\
\text { театрално и фрилмово изкуство } \\
\text { "Крьстьо Сарафров" - Софрия }\end{array}$ & 81414,00 & 83596,00 & 84529,00 \\
\hline $\begin{array}{l}\text { Национална музикална акалемия } \\
\text { "Профр. Панчо Влалигеров" - Софрия }\end{array}$ & 91017,00 & 87457,00 & 88587,00 \\
\hline $\begin{array}{l}\text { Национална художествена } \\
\text { акалемия - Софрия }\end{array}$ & 89134,00 & 97005,00 & 108004,00 \\
\hline
\end{tabular}

Фиг.4. Финансиране на научната и хуложествено-творческа Аейност 
Финансирането на тази дейност за четирите висши училища по изкуствата е представено във фии. 4. Забелязване се неустойчива тенденция във фоинансирането - при някои от университетите имаме увеличение, при други намаление на субсидията. Специориката на художествено-творческата Аейност изисква и по-различен подхол при оценката на тази Аейност от тези висши учебни заведения. Наукометричните показатели са приложими и за университетите по изкуствата, въпреки, че не са най-подходящия инструментариум. Те залагат не само на художествено-творческите си прояви, но и като университет, преполавателите развиват и научна Аейност.

\section{Заключение}

Аипсата на стратегия и еАинна визия за развитието на културата и изкуството на национално ниво съзАава труАност при изпьлнение на националната и европейската културни политики. От особено значение е приемането на стратегията и изпьлнението на поетите от Аьржавата ангажименти за създаване на условия за съхранението и устойчивото развитието на българската култура. Независимо от направените опити през годините още от 1998 Ао момента за промени, все още не разполагаме с ясно разписан стратегически Аокумент, който Аа очертава развитието на българската култура. Наясно сме, че процесът не е лек (необхолимо е съгласуване и полкрапа с парламент, правителство, общество, министерство), но приемането на стратегически Аокумент е наложително. Необходими са промени в нагласите на творците към механизмите за фонансиране на творчеството, необходими са спешни мерки, свързани с оцеляване на твореца в условията на COVID 19, необходимо е разширяване на крьгозора и на правителството и на твореца по отношение на възможностите и подкрепата на изкуството. Необходими са промени в качеството и финансирането на образованието в областта на изкуствата. 


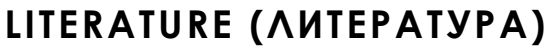

Barkalova, P., Kazashka, V. (2010). Cultural industries - a real sector of the economy and necessity. Proceedings of the VII Scientific Conference Management and Entrepreneurship TU - Plovdiv, pp. 81- 84, Plovdiv, ISBN 1313-9460. / [Бъркалова П., Казашка В., Културните индустрии - реален сектор от икономиката и необходимост. Сборник VII научна конференция МениАжмънт и предприемачество ТУ - ПАовАив, стр. 81- 84, ISBN 1313-9460].

Dobreva, N. (2018). Strategies for the Development of Culture as an Opportunity for the Bulgarian Municipalities, Report presented at the annual conference "Science in the service of society - 2018", Section of Economic Sciences, University of Economics - Varna, October 26., [Аобрева, Н. (2018). Стратегии за развитие на културата като възможност за българските общини. Аоклал преАставен на годишната конореренция „Науката в служба на обществото - 2018“, секция Икономически науки, Икономически университет - Варна, 26 октомври].

Ghilardi, L. (2001). Cultural Planning and Cultural Diversity, In: Differing Diversities: Cultural Policy and Cultural Diversities. Tony Bennet Ed., Council of Europe Publications.

Kabakov, I. (2017). Integrated Management of Culture, Sofia, University publishing house "St. Kliment Ohridski", [Кабаков, И. (2017) Интегрирано управление на културата, Соория: УИ „Св. КАимент ОхриАски“].

Landry Ch. (1997). Cultural Policy in Bulgaria Report of a eurapen panel of Examiners, Consil of Europe

Mercer, C. (1991). Brisbane's Cultural Development Strategy: the Process, the Politics and the Product, In: EIT Pty Ltd., In The Cultural Planning Conference. Morningon, Vic.: Engineering Publications.

Vesela kAZAShKa, Assoc. Prof. Dr. vesela.kazashka@gmail.com Academy of Music, Dance and Fine Arts "Prof. Asen Diamandiev" Plovdiv, Bulgaria 

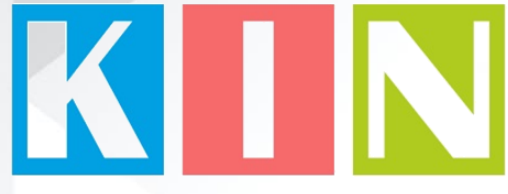

\section{ISSN: 2367-8038}

\section{Съставители \\ Петко Ст. Петков \\ Галина БогАанова}

Материалите в сборника са обект на авторско право. Разрешава се безвъзмезАното ползване на техни електронни/ хартиени копия само за мична употреба или обучение, при пьлно цитиране на текущата страница и слеА писмена Аек^арация от цитиращия за ^ипса на търговски намерения.

Научната поредица е регистрирана в НАЦИА С № 1209

() Авторски колектив, 2021

Техническо реАактори: Калина Сотирова-Вълкова Николай Ноев Паска^ Пиперков

\section{Editors}

Petko St. Petkov

Galina Bogdanova

This work is subject to copyright.

Open and free of charge use of digital/hard copies of publications is granted only for personal or educational use, with full citation of the current page, and after written declaration of the quoting side for notcommercial Intention.

Science series has been registered in NACID with No. 1209

() Authors` Group, 2021

Technical editors:

Kalina Sotirova-Valkova

Nikolay Noev

Paskal Piperkov

\section{ISSN: 2367-8038}

том 7, брой $1(10) / 2021$

vol. 7 , issue $1(10) / 2021$ 